\title{
A Methodology for Determining Suitable Heat-unit Requirements for Harvest of Highbush Blueberry
}

\author{
J.D. Carlson' \\ Department of Entomology, Department of Agricultural Engineering, Michigan State University, \\ East Lansing, MI 48824 \\ J.F. Hancock, Jr. ${ }^{2}$ \\ Department of Horticulture, Michigan State University, East Lansing MI 48824 \\ Additional index words. degree days, Vaccinium corymbosum, crop modeling
}

\begin{abstract}
Fifteen years of Michigan harvest data for highbush blueberry (Vacciniun corymbosum L.) were used in conjunction with daily maximum and minimum temperatures to determine appropriate heat-unit models for firstpicking dates of 13 cultivars. For each cultivar, an optimal heat-unit model was chosen after evaluating the performance of a standard method with 72 combinations of three variables: a) starting date for the heat-unit accumulations (SDATE), b) low-temperature threshold (TLOW), and c) high-temperature threshold (THIGH). The optimal model sought to include the most important criteria values with respect to model performance and to minimize the average square of the prediction error (days) and the range in that error. Compared with a strict calendar-day method of estimating harvest dates, the heat-unit models reduced the standard deviation of the prediction error from $22 \%$ to $69 \%$, depending on cultivar.
\end{abstract}

The influence of weather on the phenology and yield of a crop has been quantitatively documented for various agriculturally important species. One of the documented variables is an index of heat accumulation above a threshold temperature that is usually specific to the crop in question and thought to be closely related to the physiological "base" temperature above which development occurs. An upper temperature threshold, above which development decreases or shuts off, may also be appropriate, such as with corn (Gilmore and Rogers, 1958). In the case of an annually planted crop, the calculated heat accumulations generally begin at time of planting, while for a perennial crop they are usually begun at a selected calendar date early in the growing season.

The "heat-unit" system has been used for a wide range of crops, including those in horticulture. Vegetables for which heat units have seen use include peas (Katz, 1952), lettuce (Madariaga and Knott, 1951), and cucumbers (Perry and Wehner, 1990; Perry et al., 1986). Fruits represented include apples, pears, peaches, apricots, prunes, and sweet cherries (Anstey, 1966; Baker and Brooks, 1944; Fisher, 1962; Partridge, 1947; Richardson et al., 1975; Sisler and Overholser, 1943); sour cherries (Eisensmith et al., 1980); and grapes (Van Den Brink, 1974; Winkler and Williams, 1939).

The highbush blueberry is an important specialty crop in a number of states in the eastern, Midwestern, mid-Atlantic, and northwestern sections of the United States (Hancock and Draper, 1989). Of these states, Michigan has been the leader in production in recent decades. Average highbush production during the $1984-88$ period was $22.7 \mathrm{t}$, more than a quarter of the total U.S. and Canadian cultivated blueberry production of $88.0 \mathrm{t}$ (Ricks and Thomas, 1989). While research has related temper-

Received for publication 15 Oct. 1990. This research was partially supported by a grant from MBG Marketing, Grand Junction, Mich. The cost of publishing this paper was defrayed in part by the payment of page charges. Under postal regulations, this paper therefore must be hereby marked advertisement solely to indicate this fact.

'Assistant Professor. Present address: Dept. of Agricultural Engineering, Oklahoma State Univ., Stillwater, OK 74078.

${ }^{2}$ Professor. ature to such phenological events as chilling, budbreak, and flowering in blueberry (Austin et al., 1982; Darrow, 1942; Gilreath and Buchanan, 1981; Mainland, 1985; Mainland et al., 1977; Norvell and Moore, 1982; Spiers, 1976; Spiers and Draper, 1974), as well as to $\mathrm{CO}_{2}$ assimilation and water-use efficiency (Moon et al., 1987a, 1987b), no research to these authors' knowledge has related heat-unit accumulation to harvest date for this important horticultural specialty crop.

The objective of this research was to develop optimal heatunit models for predicting harvest date for a number of highbush blueberry cultivars commonly grown in the northern production regions. An additional focus of the research concerned a more general issue: How does one select a suitable heat-unit model for predicting phonological development for a given crop cultivar?

\section{Materials and Methods}

Databases. The biological database for first-picking dates for highbush blueberry in Michigan came from the research test plots of the Michigan Blueberry Growers Assn. at Grand Junction, Mich. (42 $43^{\prime} \mathrm{N}, 86^{\circ} 5^{\prime} \mathrm{W}, 208-\mathrm{m}$ elevation). Fifteen years (1974-88) of data were used for 12 cultivars: Berkeley, Bluecrop, Bluejay, Blueray, Bluetta, Collins, Coville, Earliblue, Elliott, Jersey, Rubel, and Spartan. Ten years (1978-82, 198488) of data were used for 'Patriot'. Average first-picking dates range from 8 July for 'Earliblue' to 26 Aug. for 'Elliott' (Table 3).

The meteorological database consisted of daily maximum and minimum temperatures (recorded by sheltered thermometers at $1.5 \mathrm{~m}$ above the ground) from nearby sites for Feb. through Sept. 1974-88. Data for February and March came from the published National Weather Service (NWS) climatological station at Bloomingdales, Mich. (U.S. Dept. of Commerce, 19741988). Data for April through September came from the NWS agricultural weather station at Grand Junction. Both sites are

Abbreviations: THIGH, high-temperature threshold; TLOW, low-temperature threshold; SDATE, starting date for heat-unit accumulations. 
located in rural settings with similar characteristics to the location of the test plots, the Bloomingdales site being $\approx 10 \mathrm{~km}$ away (221-m elevation) and the Grand Junction site being only $0.6 \mathrm{~km}$ away (209-m elevation).

A wide variety of weather occurred during the years of analysis. For April through August, the average mean ranged from 15C $(1976,1979,1982)$ to $18 \mathrm{C}(1987)$, with number of days having maxima $>32 \mathrm{C}$ ranging from $0(1979,1981)$ to $30(1988)$. Precipitation during the 5 months varied from only $260 \mathrm{~mm}$ in 1988 to $690 \mathrm{~mm}$ in 1980 . With respect to general climatic conditions for 1951-80, the mean at Bloomingdales, Mich., ranges from $-5 \mathrm{C}$ in January to $22 \mathrm{C}$ in July, with an annual mean of 9C. The average date of the last spring occurrence of $0 \mathrm{C}$ is on 10 May, with the average first fall occurrence of $0 \mathrm{C}$ being on 8 Oct. Normal precipitation for the year is $970 \mathrm{~mm}$.

Heat-unit models. The daily heat units used in the analysis were calculated via the Baskerville-Emin (B-E) method using both lower and upper temperature thresholds (Baskerville and Emin, 1969). The heat units were generated from the area under the daily temperature curve (assumed a sine wave) lying between the lower and upper temperature thresholds. Other heatunit methods could have been used or tested, but the focus of the research was not to test a variety of methods but rather to take a standard method and find an "optimal" model for each blueberry cultivar by investigating different combinations of variables associated with that method.

Given the heat-unit method, the research thus focused on determining optimal heat-unit models for each of the 13 blueberry cultivars studied. In particular, three model variables associated with the B-E method were investigated: 1) SDATE, 2) TLOW, and 3) THIGH.

Three values for SDATE were chosen: 1 Feb., 1 Mar., and 1 Apr. This variable seeks to estimate the average starting date for annual development of a given blueberry cultivar, a date that occurs after the chilling requirement has been met. Chilling requirements for highbush blueberry are estimated anywhere between 650 and $1200 \mathrm{~h}$ below 7.2C (Darrow, 1942; Hancock and Draper, 1989; Mainland, 1986). In southwestern Michigan, such duration requirements for temperatures between 0 and $7 \mathrm{C}$ will usually be met sometime during December (in the case of the first quarter of the hourly range) or from February through mid-March (in the case of the last three-quarters); January adds negligibly to the hour requirements since normal daily maxima are always < 0C. Thus, choices for SDATE of 1 Feb., 1 Mar., and 1 Apr. seemed logical candidates.

Six values for TLOW were selected: $-6.7 \mathrm{C},-3.9 \mathrm{C},-1.1 \mathrm{C}$, 1.7C, $4.4 \mathrm{C}$, and $7.2 \mathrm{C}$, all originally based on $5 \mathrm{~F}$ intervals. This variable seeks to determine whether a given cultivar responds only to air temperatures well above freezing, or if it can begin development with temperatures considerably below freezing. Personal experience with blueberry plants in growth chambers has indicated bud development can occur with temperatures considerably < 0C; Addison (1969), in a limited study using only 3 years of data, showed the best relationship between heat units and harvest date of highbush blueberry in Michigan occurred with a lower threshold of $-4 \mathrm{C}$, the lowest temperature tested. Thus, TLOW candidates extending as low as $-7 \mathrm{C}$ were considered.

Finally, four values for THIGH were chosen: $21.1 \mathrm{C}, 26.7 \mathrm{C}$, $32.2 \mathrm{C}$, all based on 10F intervals, and no upper threshold. This variable seeks to test whether a given cultivars development is inhibited by high temperatures or whether such temperatures are of no detrimental effect. Laboratory studies have shown inhib- ited $\mathrm{CO}_{2}$ assimilation $>22 \mathrm{C}$ in the case of 'Bluecrop' and $>26 \mathrm{C}$ in the case of 'Jersey' (Moon et al., 1987a, 1987b).

Statistical approach. In similar phonological investigations in the past, several statistics and variables have been used to aid in the choice of a suitable heat-unit model. One such variable is the heat-unit accumulation between starting and harvest dates. For a given cultivar, each model yields a set of $\mathrm{N}$ heat-unit accumulations representing the $\mathrm{N}$ years of data. Arnold (1959) has shown that the standard deviation (SDEV) of this variable is an invalid statistic to use, since for two equally good models (i.e., same SDEV of prediction error in days) the one having the lower base temperature (or earlier starting date) has the greater SDEV. He postulated that the coefficient of variation $(\mathrm{cv}=100 * \mathrm{SDEV} / \mathrm{MEAN})$ is the appropriate statistic to use in comparing models. His recommendation has occasionally seen use in the literature (e.g., Gilmore and Rogers, 1958; Perry et al., 1986). However, this statistic can also lead to spurious conclusions, since it can be shown that for two equivalent models the $\mathrm{cv}$ is higher for that model with a higher base temperature or later starting date (in such cases, the heat-unit mean decreases more quickly than does SDEV). Anstey (1966) recognized this fact and, rather than using the lowest cv value as the criterion, chose the model at which the cv "surface" changed direction most rapidly. Years earlier, Partridge (1947) also saw the fallacy of using the $\mathrm{cv}$ in certain cases and adopted an approach similar to the one selected for the present research.

Since, as far as producers are concerned, closeness (in days) of the predictions to the actual harvest dates is the important aspect, it makes sense to choose the deviation in days (or some variation of it) as the variable to look at in selecting a model. For each cultivar and model (hereby defined as one of the 72 combinations of SDATE, TLOW, and THIGH), a harvest predictor $\mathrm{HUm}$ is calculated, which is the average of the heat-unit accumulations between starting date and harvest date for each of the $\mathrm{N}$ years of data. Here, harvest date denotes the firstpicking date, defined as the time when $\approx 75 \%$ of the berries are blue. Then, for a given year, the predicted Julian date $\left(\mathrm{JD}_{\mathrm{p}}\right)$ for harvest becomes the date for which the actual heat-unit total since the selected starting date equals HUm. For each cultivar and model, then, we have a set of predicted $\left(\mathrm{JD}_{\mathrm{P}}\right)$ and actual $\left(\mathrm{JD}_{\mathrm{a}}\right)$ harvest dates covering $\mathrm{N}$ years. For a given cultivar, a deviation DEV for the $i^{\text {th }}$ year of predicted from actual harvest date can then be defined:

$$
\operatorname{DEV}(\mathrm{i})=\operatorname{JD}_{\mathrm{p}}(\mathrm{i})-\mathrm{JD}_{\mathrm{a}}(\mathrm{i})
$$

One could, as did Partridge (1947) and Perry and Wehner (1990), look at the statistics of DEV as a basis for model evaluation. For many horticultural crops that spoil within a few days of ripening, an underprediction of harvest date (negative DEV) might be more desirable than an overprediction (positive DEV); one might thus want to assign a weighting factor $>1$ to positive deviations. For blueberries, however, which can, depending on cultivar and temperature conditions, last 7 to 14 days on the bush without spoiling, it was decided to use weights of 1 for both positive and negative DEV values.

Another possibility is to look at which method results in the lowest range (RANGE) between the most positive DEV and the most negative DEV:

$$
\text { RANGE }=\operatorname{DEV}(\mathrm{i}) \max -\operatorname{DEV}(\mathrm{i}) \min
$$

Perhaps a more important variable is DEV2, the square of the deviation:

$$
\operatorname{DEV} 2(\mathrm{i})=[\mathrm{DEV}(\mathrm{i})]^{2}
$$


This variation is also a measure of the error of prediction, but it penalizes outliers (extremely large predictive errors that producers wish to avoid) more severely than the simple deviation. Here, one might look at which method results in the lowest value of DEV2, the average of DEV2(i).

Closely related to the average squared deviation, $\overline{\mathrm{DEV} 2}$ is the coefficient of determination $\left(r^{2}\right)$ between the actual and predicted harvest dates:

$$
\mathrm{r}^{2}=1-\mathrm{N}(\overline{\mathrm{DEV} 2}) / \mathrm{k}
$$

where $\mathrm{N}$ is the number of years of data and $\mathrm{k}$ is the total squared error of actual harvest date about its average. For a given cultivar and heat-unit model, this $r^{2}$ can also be thought of as a measure of the accuracy of fit of the line "actual date = predicted date" (i.e., the "perfect" model).

Method of analysis. To determine the effect of each variable on performance, the following procedures were used. To investigate the effect of starting date, the 72 models were divided into three groups according to SDATE value (i.e., all models having a starting date of 1 Feb. in one grouping, etc.). $r^{2}$ values for each grouping were calculated by averaging the individual model $r^{2}$ values within each group. The SDATE values were then ranked from highest to lowest $r^{2}$. Similar procedures were used to investigate the effects of low- and high-temperature threshold, with the 72 models being divided into six, then four groups, respectively. Table 1 lists the value rankings for these variables and the maximum and minimum $r^{2}$ values and their difference DELTA.

For a given blueberry cultivar, the DELTA values indicate the sensitivity of model performance to each of the three variables. The more important variables for biological development will produce a larger range in $r^{2}$ values than will the less important ones. Note that we are not looking at the absolute value of the $r^{2}$ values here (they are quite similar across all three variables), rather, at the differences in them resulting from altering the values of the criteria. Table 1 indicates that for all cultivars either SDATE or TLOW is most important; the second most important is in most cases the other of these two variables. For example, for 'Bluecrop' SDATE is most important (DELTA $=0.166)$, followed by TLOW (DELTA $=0.107)$, and, last, THIGH (DELTA $=0.034)$. Averaged over all cultivars, SDATE is the most important variable, producing an average range in $r^{2}$ of 0.113 , followed by TLOW with an average range of 0.084 , then, in a distant third, by THIGH with an average range of 0.029.

To reduce the number of candidates from the original 72 heatunit models, the following procedures were used with each cultivar. First, the variable having the largest value for DELTA (call this value DELMAX) was deemed the most important in the estimation of harvest date. The top two values (with respect to $r^{2}$ ) of this variable were chosen as the sole candidates of this variable for the heat-unit model. Then, the variable having the next largest DELTA was inspected. When its DELTA was $<25 \%$ of DELMAX, the variable was considered relatively unimportant and all values of that variable were allowed to be candidates for the model; when its DELTA was $\geq 25 \%$ of DELMAX, only the top two values of the variable were selected as candidates. Finally, the least important variable was considered and the same procedures followed as with the second variable. Thus, for example, the SDATE candidates for the 'Bluecrop' model were $\mathrm{F}$ (1 Feb.) and $\mathrm{M}$ (1 Mar.), the TLOW candidates were 7 and $4 \mathrm{C}$, and any value of THIGH was a candidate. While not producing a single optimal model, the above methodology gen- crates a subset of allowable models based on the relative importance of three variables associated with the temperature effect on maturation.

Since, on average, SDATE and TLOW are the two most important variables, average $r^{2}$ values were calculated for the various SDATE and TLOW combinations (all THIGH values included) and are listed in Table 2. For some cultivars (e.g., 'Bluecrop'), the inclusion of different values for SDATE and TLOW significantly affects the accuracy of estimation, while for others (e.g., 'Berkeley') there is little variation. Creating a three-dimensional plot of average $r^{2}$ as a function of SDATE and TLOW can help one visualize the model selection process described above. The SDATE and TLOW values that are selected as candidates for a given cultivar define the boundaries of the "highest" section(s) of the three-dimensional $r^{2}$ surface. As an example, Fig. 1 presents the surface for 'Bluecrop'. Here, it is easily seen that the top two candidates for each variable determined above lie beneath the highest section of the $r^{2}$ surface. Any THIGH value (not seen) is a candidate for this cultivar.

Combinations of all the candidates for each variable determined the number of allowable heat-unit models from which to choose (e.g., for 'Bluecrop' there were 2 × 2 × $4=16$ allowable models). Finally, the particular model chosen from this subset of the 72 original models was the one that met the following two criteria: 1) it fell within the top $25 \%$ of the 72 models ranked according to $\mathrm{r}^{2}$, and 2) it had the smallest RANGE of those still remaining as candidates.

The above procedures are thus designed to produce a model that, for a given cultivar, does two things: 1) adequately reflects the temperature effect on development, and 2) maximizes predictive errors through seeking to maximize $r^{2}$ and minimize RANGE. While the nature of the data prevented the use of such rigorous statistical techniques as analysis of variance, we were, nevertheless, still able to develop useful methods for predicting harvest date.

\section{Results}

Through the procedures outlined above, appropriate models were determined for each blueberry cultivar. Table 3 presents the heat-unit models (values for the three variables and the heatunit mean, $\mathrm{HU}_{\mathrm{m}}$ ) as well as the $\mathrm{r}^{2}$ values, measures of model performance. Note that the $\mathrm{r}^{2}$ values range from a low of 0.39 for 'Berkeley' to a high of 0.90 for 'Patriot'.

Table 3 also presents, for each cultivar, a comparison of results from the chosen heat-unit model vs. a calendar-day model, in which harvest date is predicted to be the same day (HDATE) every year. As harvest nears, some producers adjust this date according to bloom date or personal experience, but for comparison with the heat-unit model we chose a fixed calendar day, since we had neither bloom dates nor producers' experience available during the period of record. For each cultivar, Table 3 presents a variable $u$ representing the accuracy of each model. This latter variable is the standard deviation of the time error (DEV) between predicted and actual harvest dates and is defined as follows:

$$
\sigma=\sqrt{[\operatorname{sum}(\overline{\operatorname{DEV}(\mathrm{i}) 2)] /(\mathrm{N}-1)}}
$$

Here, $\mathrm{N}$ represents the number of years of data, $\mathrm{i}$ represents the $i^{\text {th }}$ year, and sum denotes the summation over all the $i$ years ( $i$ $=1$ to $\mathrm{N}$ ). The ratio of the two $ð$ values, $\partial_{\mathrm{hU}}$ : $\partial_{\text {cal }}$, is also given. 
Table 1. Effect of three variables (SDATE, TLOW, and THIGH) upon heat-unit model performance. For each variable, the 72 models were grouped by variable value and ranked from highest to lowest average $r^{2}$ values. The maximum and minimum $r^{2}$ values are listed as well as their difference DELTA. Variable value rankings are listed from highest to lowest average $r^{2}$. TLOW and THIGH are in ${ }^{\circ} \mathrm{C} ; \mathrm{F}$, $\mathrm{M}$, and A denote 1 Feb., 1 Mar., and 1 Apr., respectively.

\begin{tabular}{|c|c|c|c|}
\hline Cultivar & SDATE & TLOW & THIGH \\
\hline \multicolumn{4}{|l|}{ Berkeley } \\
\hline DELTA $\left(\max , \min r^{2}\right)$ & $0.053(0.36,0.31)$ & $0.063(0.36,0.29)$ & $0.012(0.35,0.34)$ \\
\hline Rank of variable values & $\mathrm{F}, \mathrm{M}, \mathrm{A}$ & $-4,-7,2,-1,4,7$ & 27,32, no, 21 \\
\hline \multicolumn{4}{|l|}{ Bluecrop } \\
\hline DELTA $\left(\max , \min r^{2}\right)$ & $0.166(0.67,0.51)$ & $0.107(0.66,0.55)$ & $0.034(0.62,0.58)$ \\
\hline Rank of variable values & $\mathrm{F}, \mathrm{M}, \mathrm{A}$ & $7,4,2,-1,-4,-7$ & 32,27, no, 21 \\
\hline \multicolumn{4}{|l|}{ Bluejay } \\
\hline DELTA $\left(\max , \min r^{2}\right)$ & $0.084(0.69,0.60)$ & $0.090(0.69,0.60)$ & $0.011(0.66,0.65)$ \\
\hline Rank of variable values & $\mathrm{M}, \mathrm{F}, \mathrm{A}$ & $4,2,7,-1,-4,-7$ & 27,32, no, 21 \\
\hline \multicolumn{4}{|l|}{ Blueray } \\
\hline DELTA $\left(\max , \min r^{2}\right)$ & $0.079(0.35,0.28)$ & $0.115(0.35,0.24)$ & $0.084(0.36,0.28)$ \\
\hline Rank of variable values & $\mathrm{F}, \mathrm{M}, \mathrm{A}$ & $-7,-4,-1,2,4,7$ & $21,27,32$, no \\
\hline \multicolumn{4}{|l|}{ Bluetta } \\
\hline DELTA $\left(\max , \min r^{2}\right)$ & $0.096(0.68,0.58)$ & $0.073(0.67,0.60)$ & $0.014(0.65,0.63)$ \\
\hline Rank of variable values & $\mathrm{M}, \mathrm{F}, \mathrm{A}$ & $4,2,7,-1,-4,-7$ & 32, no, 27,21 \\
\hline \multicolumn{4}{|l|}{ Collins } \\
\hline DELTA $\left(\max , \min r^{2}\right)$ & $0.091(0.44,0.35)$ & $0.023(0.41,0.39)$ & $0.020(0.40,0.38)$ \\
\hline Rank of variable values & $\mathrm{F}, \mathrm{M}, \mathrm{A}$ & $-7,-4,2,-1,4,7$ & 32,27, no, 21 \\
\hline \multicolumn{4}{|l|}{ Coville } \\
\hline DELTA $\left(\max , \min r^{2}\right)$ & $0.265(0.65,0.38)$ & $0.050(0.56,0.51)$ & $0.055(0.56,0.50)$ \\
\hline Rank of variable values & $\mathrm{F}, \mathrm{M}, \mathrm{A}$ & $-4,-1,-7,2,4,7$ & 32, no, 27,21 \\
\hline \multicolumn{4}{|l|}{ Earliblue } \\
\hline DELTA $\left(\max , \min r^{2}\right)$ & $0.047(0.73,0.68)$ & $0.099(0.74,0.64)$ & $0.028(0.72,0.69)$ \\
\hline Rank of variable values & $\mathrm{M}, \mathrm{A}, \mathrm{F}$ & $4,2,7,-1,-4,-7$ & $21,27,32$, no \\
\hline \multicolumn{4}{|l|}{ Elliott } \\
\hline DELTA $\left(\max , \min r^{2}\right)$ & $0.180(0.73,0.55)$ & $0.045(0.67,0.63)$ & $0.026(0.67,0.65)$ \\
\hline Rank of variable values & $\mathrm{F}, \mathrm{M}, \mathrm{A}$ & $2,-1,4,-4,-7,7$ & $27,32,21$, no \\
\hline \multicolumn{4}{|l|}{ Jersey } \\
\hline DELTA $\left(\max , \min r^{2}\right)$ & $0.124(0.46,0.33)$ & $0.026(0.41,0.38)$ & $0.022(0.41,0.38)$ \\
\hline Rank of variable values & $\mathrm{F}, \mathrm{M}, \mathrm{A}$ & $2,4,-1,-4,-7,7$ & 27,32, no, 21 \\
\hline \multicolumn{4}{|l|}{ Patriot } \\
\hline DELTA $\left(\max , \min r^{2}\right)$ & $0.129(0.86,0.73)$ & $0.179(0.88,0.70)$ & $0.023(0.80,0.78)$ \\
\hline Rank of variable values & $\mathrm{M}, \mathrm{F}, \mathrm{A}$ & $7,4,2,-1,-4,-7$ & no, $32,27,21$ \\
\hline \multicolumn{4}{|l|}{ Rubel } \\
\hline DELTA $\left(\max , \min r^{2}\right)$ & $0.095(0.37,0.27)$ & $0.116(0.35,0.23)$ & $0.031(0.33,0.30)$ \\
\hline Rank of variable values & $\mathrm{F}, \mathrm{M}, \mathrm{A}$ & $-7,-4,-1,2,4,7$ & $27,21,32$, no \\
\hline \multicolumn{4}{|l|}{ Spartan } \\
\hline DELTA $\left(\max , \min r^{2}\right)$ & $0.059(0.53,0.47)$ & $0.111(0.53,0.42)$ & $0.018(0.50,0.48)$ \\
\hline Rank of variable values & $\mathrm{F}, \mathrm{M}, \mathrm{A}$ & $-7,-4,-1,2,4,7$ & $27,21,32$, no \\
\hline \multicolumn{4}{|l|}{ All cultivars } \\
\hline Average DELTA & 0.113 & 0.084 & 0.029 \\
\hline
\end{tabular}

Table 2. Average $r^{2}$ values for heat-unit model performance for various combinations of TLOW and SDATE (all THIGH values included).

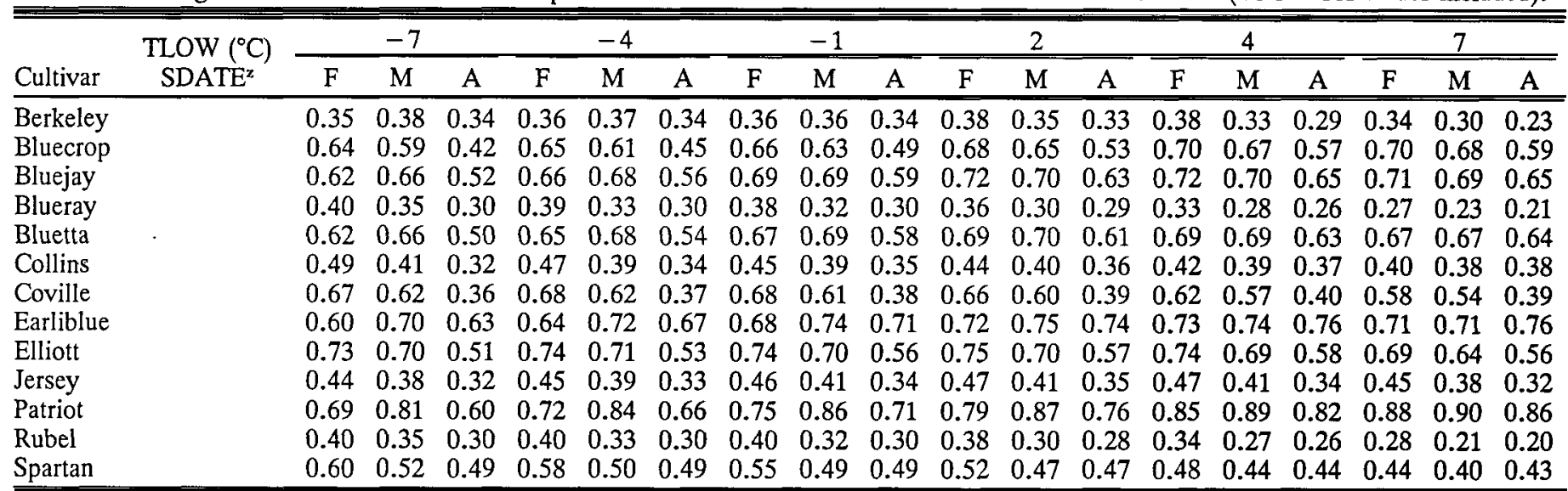

${ }^{2} \mathrm{~F}, \mathrm{M}$, and $\mathrm{A}$ denote 1 Feb., 1 Mar., and 1 Apr., respectively. 


\section{$R^{2}$ Surface for Bluecrop}

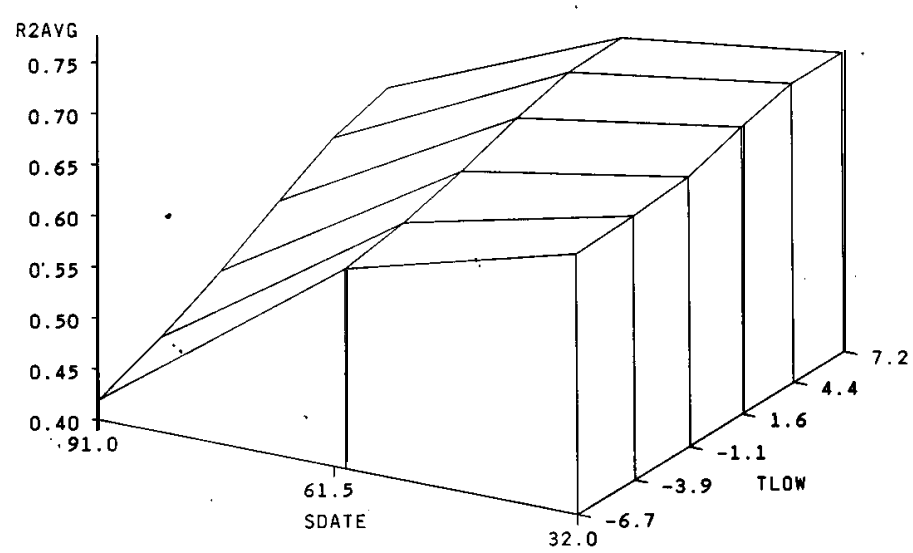

Fig. 1. Average $r^{2}$ (R2AVG) values for 'Bluecrop' heat-unit models grouped according to various combinations of SDATE and TLOW. The starting date is in Julian days and the low-temperature threshold in ${ }^{\circ} \mathrm{C}$. The top two candidates for each variable lie beneath the highest section of the $r^{2}$ surface.

Note that, in terms of actual days of prediction error, some heat-unit models are much better at predicting harvest date than others. Among the better models are those for 'Patriot' $\left(\sigma_{\text {hu }}=\right.$ 2.46 days), 'Earliblue' ( $\sigma_{\mathrm{hu}}=3.29$ days), and 'Spartan' $\left(\sigma_{\mathrm{hu}}\right.$ $=3.79$ days). Among the poorer models are those for 'Rubel' $\left(\sigma_{\text {hu }}=6.23\right.$ days $)$ and 'Jersey' $\left(\sigma_{\text {hu }}=6.97\right.$ days $)$. Also note that there is not an exact inverse relationship between these $\sigma_{\text {hu }}$ values and the $r^{2}$ values, since the $r^{2}$ values also involve the total squared error of actual harvest date about its average (Eq. [4]).

Despite their relative performances, the heat-unit models, when compared with the calendar-day method of prediction, prove superior for each cultivar. Looking at the $\boldsymbol{J}$ ratio, one can see that the improvement varies from $22 \%$ for 'Berkeley' (a $\boldsymbol{\sigma}$ of
1.52 days less) to as much as $69 \%$ for 'Patriot' (5.49 days less). The RANGE values (Eq. [2]), not listed in Table 3, are also lower for each cultivar in the heat-unit model.

In this analysis, the heat-unit models used actual temperature data up to the dates of prediction and thus might be expected to perform better than the calendar-day models. To be useful, the heat-unit models would need to predict harvest before it actually occurs (i.e., using actual temperature data followed by the latest temperature forecasts and/or historical norms through the days and weeks ahead). While not tested in this mode, the heat-unit approach would, we hope, still prove superior to a calendar-day approach.

\section{Discussion}

The two most important variables, averaged over all cultivars, are the starting date for the heat-unit accumulation and the low temperature threshold (Table 1). By grouping the 72 models tested into 18 specific (SDATE, TLOW) combinations (all THIGH values included), one can generate a table of average $\mathrm{r}^{2}$ values (Table 2) and $\mathrm{r}^{2}$ surfaces such as Fig. 1. Note in Fig. 1 that 'Bluecrop' heat-unit models perform better (higher $r^{2}$ values) as one moves toward lower SDATE and toward higher TLOW values. Such results may indicate that the chilling requirement for 'Bluecrop' to break winter rest is usually met by $1 \mathrm{Feb}$. in Michigan, and that this cultivar is ready to begin development by then, albeit at temperatures on the high end of those selected for testing.

A starting date of $1 \mathrm{Feb}$. produces the highest $\mathrm{r}^{2}$ values across all values of TLOW in the following cultivars: Bluecrop, Blueray, Collins, Coville, Elliott, Jersey, Rubel, and Spartan (Table 2). Most of these cultivars are able to develop at TLOW values as low as - 7C (as evidenced by higher $r^{2}$ ), although 'Bluecrop' appears to require higher temperatures for development; 'Elliott' and 'Jersey' show little sensitivity to TLOW. 'Berkeley', 'Bhreray', and 'Bluetta' seem to do equally well with starting dates of 1 Feb. or 1 Mar. 'Bluejay' and 'Bluetta' require higher temperatures for development, while 'Berkeley' is insensitive to TLOW. Finally, 'Patriot' and 'Earliblue' evidence delayed development with optimal starting dates of 1 Mar. for 'Patriot'

Table 3. The selected heat-unit models and their associated statistics for predicting first-picking date of highbush blueberry. Also included is a comparison with the calendar-day models. SDATE denotes the starting date for heat-unit accumulations; TLOW and THIGH, the low- and high-temperature thresholds, respectively; $\mathrm{HU}_{\mathrm{m}}$, the average heat units from SDATE to harvest; $r^{2}$, the coefficient of determination; and $\sigma$, the standard deviation of the time error (days) between predicted and actual harvest dates. HDATE denotes the average first-picking date for that cultivar over the years of data.

\begin{tabular}{|c|c|c|c|c|c|c|c|c|c|}
\hline \multirow[b]{2}{*}{ Cultivar } & \multicolumn{6}{|c|}{ Heat-unit model } & \multirow[b]{2}{*}{$\sigma_{\mathrm{hu}} / \sigma_{\mathrm{cal}}$} & \multicolumn{2}{|c|}{ Calendar-day model } \\
\hline & SDATE & $\begin{array}{c}\text { TLOW } \\
\left({ }^{\circ} \mathrm{C}\right)\end{array}$ & $\begin{array}{c}\text { THIGH } \\
\left({ }^{\circ} \mathrm{C}\right)\end{array}$ & $\mathrm{HU}_{\mathrm{m}}$ & $r^{2}$ & $\begin{array}{c}\sigma_{\mathrm{hu}} \\
\text { (days) }\end{array}$ & & $\begin{array}{c}\sigma_{\text {cal }} \\
\text { (days) }\end{array}$ & HDATE \\
\hline Berkeley & 1 Mar. & -7 & 32 & 2960 & 0.39 & 5.43 & 0.78 & 6.95 & 1 Aug. \\
\hline Bluecrop & 1 Feb. & 7 & 27 & 1047 & 0.71 & 5.08 & 0.54 & 9.48 & 28 July \\
\hline Bluejay & 1 Feb. & 2 & 21 & 1495 & 0.71 & 4.69 & 0.54 & 8.75 & 23 July \\
\hline Blueray & 1 Feb. & -7 & 27 & 2943 & 0.41 & 5.38 & 0.77 & 7.00 & 28 July \\
\hline Bluetta & $1 \mathrm{Feb}$. & 4 & 21 & 970 & 0.70 & 4.10 & 0.55 & 7.43 & 9 July \\
\hline Collins & $1 \mathrm{Feb}$. & -7 & 21 & 2478 & 0.49 & 5.28 & 0.72 & 7.37 & 14 July \\
\hline Coville & 1 Feb. & -7 & No & 3224 & 0.69 & 4.49 & 0.56 & 8.03 & 7 Aug. \\
\hline Earliblue & 1 Mar. & 4 & 21 & 958 & 0.77 & 3.29 & 0.48 & 6.89 & 8 July \\
\hline Elliott & $1 \mathrm{Feb}$. & 2 & 21 & 2068 & 0.75 & 4.30 & 0.50 & 8.59 & 26 Aug. \\
\hline Jersey & $1 \mathrm{Feb}$. & $-\overline{7}$ & 32 & 3336 & 0.45 & 6.97 & 0.74 & 9.40 & 11 Aug. \\
\hline Patriot & 1 Mar. & 7 & 21 & 859 & 0.90 & 2.46 & 0.31 & 7.95 & 21 July \\
\hline Rubel & $1 \mathrm{Feb}$. & -7 & 27 & 3100 & 0.41 & 6.23 & 0.77 & 8.08 & 3 Aug. \\
\hline Spartan & 1 Feb. & -7 & 21 & 2487 & 0.60 & 3.79 & 0.64 & 5.96 & 15 July \\
\hline Average & & & & & 0.61 & 4.73 & 0.60 & 7.84 & \\
\hline
\end{tabular}


and 1 Mar. or even 1 Apr. for 'Earliblue'. These two cultivars also appear to require higher temperatures for growth.

Even though THIGH, the upper temperature threshold, is the least important variable, it is interesting to note that, according to Table 1, all cultivars except 'Patriot' have higher $r^{2}$ values with models using some upper temperature threshold; $21 \mathrm{C}$ is the leading upper temperature value for two cultivars; $27 \mathrm{C}$ for six; and $32 \mathrm{C}$ for four. Thus, it appears that high maximum temperatures do inhibit development of most highbush blueberry cultivars to some extent.

Finally, this research shows the potential superiority of the heat-unit method over a strict calendar-day method in real-time forecasting of harvest date for highbush blueberry. For locations other than Michigan, the particular variable values of the cultivar models would most likely need to be changed, especially the SDATE values in the case of a substantially different climate. The proof of the selected models' validity will be their performance over time. These models will need to be tested in the field and possibly revised, if needed. The potential exists for such models to become useful tools to blueberry producers and marketers, who could rely on model forecasts to increase accuracy in the scheduling of labor, mechanical harvesters, supplies, and marketing thrusts.

\section{Literature Cited}

Addison, E.S. 1969. Forecast of blueberry harvest dates as determined by climatology. MS Thesis, Rutgers Univ., New Brunswick, N.J.

Anstey, T.H. 1966. Prediction of full bloom date for apple, pear, cherry, peach, and apricot from air temperature data. Proc. Amer. Soc. Hort. Sci. 88:57-66.

Arnold, C.Y. 1959. The determination and significance of the base temperature in a linear heat unit system. Proc. Amer. Soc. Hort. Sci. 74:430-445.

Austin, M. E., B.G. Mullinix, and J.S. Mason. 1982. Influence of chilling on growth and flowering of rabbiteye blueberries. HortScience 17:768-769.

Baker, G.A. and R.M. Brooks. 1944. Climate in relation to deciduous fruit production in California. III. Effects of temperature on number of days from full bloom to harvest of apricot and prune fruits. Proc. Amer. Soc. Hort. Sci. 45:95-104.

Baskerville, G.L. and P. Emin. 1969. Rapid estimation of heat accumulation from maximum and minimum temperatures. Ecology 50:514517.

Darrow, G.M. 1942. Rest period requirements of blueberries. Proc. Amer. Soc. Hort. Sci. 41:189-194.

Eisensmith, S. P., A.L. Jones, and J.A. Flore. 1980. Predicting leaf emergence of 'Montmorency' sour cherry from degree-day accumulations. J. Amer. Soc. Hort. Sci. 105:75-78.

Fisher, D.V. 1962. Heat units and number of days required to mature some pome and stone fruits in various areas of North America. Proc. Amer. Soc. Hort. Sci. 80:114-124.

Gilmore, E. C., Jr., and J.S. Rogers. 1958. Heat units for measuring maturity in corn. Agron. J. 50:611-615.
Gilreath, P.R. and D.W. Buchanan. 1981. Temperature and cultivar influences on the chilling period of rabbiteye blueberry. J. Amer. Soc. Hort. Sci. 106:625-628.

Hancock, J.F. and A.D. Draper. 1989. Blueberry culture in North America. HortScience 24:551-556.

Katz, Y.H. 1952. The relationship between heat unit accumulation and the planting and harvesting of canning peas. Agron. J. 44:74-78.

Madariaga, F.J. and J.E. Knott. 1951. Temperature summations in relation to lettuce growth. Proc. Amer. Soc. Hort. Sci. 58:147-152.

Mainland, C.M. 1985. Flowering and fruiting in a warm climate. Acts Hort. 165:29-34.

Mainland, C.M. 1986. Commercial blueberry production guide for North Carolina. North Carolina Agr. Expt. Sta., Raleigh.

Mainland, C. M., D.W. Buchanan, and J.F. Bartholic. 1977. The effects of five chilling regimes on bud break of highbush (Vacciniun corymbosum L.) and rabbiteye (V. ashei Reade) blueberry hardwood cuttings. HortScience 12:411. (Abstr.)

Moon, J. W., J.A. Flore, and J.F. Hancock, Jr. 1987a. A comparison of carbon and water vapor gas exchange characteristics between a diploid and highbush blueberry. J. Amer. Soc. Hort. Sci. 112:134138.

Moon, J. W., J.F. Hancock, Jr., A.D. Draper, and J.A. Flore. 1987b. Genotypic differences in the effect of temperature on $\mathrm{CO}_{2}$ assimilation and water use efficiency in blueberry. J. Amer. Soc. Hort. Sci. 112:170-173.

Norvell, D.J. and J.N. Moore. 1982. An evaluation of chilling models for estimating rest requirements of highbush blueberries (Vaccinium corymbosum L.). J. Amer. Soc. Hort. Sci. 107:54-56.

Partridge, N.L. 1947. A method for the estimation of the advancement of vegetation by the use of daily maximum temperatures. Proc. Amer. Soc. Hort. Sci. 49:7-14.

Perry, K.B. and T.C. Wehner. 1990. Prediction of cucumber harvest date using a heat unit model. HortScience 25:405-406.

Perry, K. B., T.C. Wehner, and G.L. Johnson. 1986. Comparison of 14 methods to determine heat unit requirements for cucumber harvest. HortScience 21:419-423.

Richardson, E. A., S.D. Seeley, D.R. Walker, J.L. Andersen, and G.L. Ashcroft. 1975. Pheno-climatology of spring peach bud development. HortScience 10:236-237.

Ricks, D.J. and T.M. Thomas. 1989. Supply and demand trends in the blueberry industry. Great Lakes Fruit Growers News, Jan. 8-10.

Sisler, G.P. and E.L. Overholser. 1943. Influence of climatic conditions on date of full bloom of delicious apples in the Wenatchee Valley. Proc. Amer. Soc. Hort. Sci. 43:29-34.

Spiers, J.M. 1976. Chilling regimens affect bud break in 'Tifblue' rabbiteye blueberry. J. Amer. Soc. Hort. Sci. 101:84-86.

Spiers, J.M. and A.D. Draper. 1974. Effect of chilling on bud break in rabbiteye blueberry. J. Amer. Soc. Hort. Sci. 99:398-399.

U.S. Department of Commerce. 1974-1988. Climatological data, Michigan. vol. 89-103. Natl. Climate Data Ctr., Asheville, N.C.

Van Den Brink, C. 1974. Predicting harvest date of the 'Concord' grape crop in southwest Michigan. HortScience 9:206-208.

Winkler, A.J. and W.O. Williams. 1939. The heat required to bring Tokay grapes to maturity. Proc. Amer. Soc. Hort. Sci. 37:650-652. 